\title{
BETWEEN BEING AND BECOMING: THE LANGUAGE OF METAPHYSICS IN ARCHITECTURE
}

\section{A B S T R A C T}

The use of platonic solids like cubes, spheres and pyramids, and a certain sense of "timelessness" are some of the most recognisable ways in which metaphysics has been interpreted as a formal language within the domain of architecture, particularly since the emergence of the avant-gardes at the beginning of the twentieth century. Starting by critically confronting different ways of interpreting this relationship, this paper proposes a specific phenomenological approach on the subject, focused on the analysis of the concept of timelessness and the possible theoretical foundations of its distinctive role in articulating the metaphysical expression in architecture.

\section{Juan Almarza Anwandter}

Institute for Architecture, TU Berlin

almarzaanwandter@campus.tu-berlin.de
KEY WORDS

ARCHITECTURE

METAPHYSICS

PHENOMENOLOGY

TIME

TIMELESSNESS 
"I have translated the last lines of a Hölderlin poem ("Halfte des Lebens") into my architecture: 'Die Mauern stehen / Sprachlos und kalt / im Winden ..."

Aldo Rossi

\section{ABOUT THE CONCEPT OF METAPHYSICS}

Within the Western philosophical tradition, metaphysics is the specific field of philosophy oriented to find an answer to the fundamental question about the essence of reality and its entities. In historical terms, this question has undergone different stages of development: from its initial pre-Socratic interpretations as arkhé (a material irreducible principle) to its gradual postAristotelian consolidation as a system of thought and a model of interpretation of reality, which puts the essence of being and truth in a transcendental realm situated beyond sensitive experience, "beyond physis". In this interpretation, the specific contribution of Plato's theory of ideas has played a major role, constituting one of the main forces to influence the development of Western philosophy, until Nietzsche.

This "perennial Platonism", following the definition given by Karsten Harries, has been, in turn, a prevailing paradigm within the domain of arts, understood as forms of manifestation of ideas or concepts that can acquire corporeal presence through a specific material substratum, but always transcend it. The hierarchical subordination of the material principle to the idea, which appears as the true provider of its potential meaning, as an angel that brings a "redeeming light" from above and beyond, is one of the clearest manifestations of the prevalence of metaphysical thought in the field of Western artistic production.

\section{ON METAPHYSICS AS AN AGENT}

IN THE ARCHITECTURAL DESIGN PROCESS

When it comes to architecture, the long shadow of this "angel that brings light from above and beyond" has been particularly intense. Since the Greeks, ideals of mathematical perfection, formal coherence, unity between parts and whole, harmony, etc., have constituted a priori concepts of any design process. In the form of canons of proportions, for example, they effectively transcend their specific material incarnations, constituting a set of preliminary constrictions (Fig. 1). The internal laws of these sets of constrictions may change, from style to style, from one epoch to another, but they seem to be there, always, as models that pre-define and precede the execution of the architectural form. In this 
sense, they constitute an unavoidable "metaphysical substratum" that cannot be detached, an invisible layer that cannot be deleted. A layer that today, due to the incorporation of digital technologies that combine modeling and execution stages, tends to become closer and materialises itself in the form of real-time algorithms and dynamic-responsive parametric models. Through contemporary technology, the gap between idealisation and material conformation narrows, as a consequence of the will of immediateness and instantaneity that characterises the spirit of our epoch. Does this loss of distance and blurring of the limits between idea and material form imply that the metaphysical substratum in its traditional sense is overcome? If the angel gets too close, he loses his "angelical" status.

\section{DERRIDA AND ARCHITECTURE AS "THE LAST STRONGHOLD OF METAPHYSICS"}

This is a first way to understand the role of metaphysics within architecture, as an irreducible agent of the design process. A second way is the one proposed by Jacques Derrida through his mythical statement: "Architecture is the last stronghold of metaphysics", formulated in the context of his collaboration with Bernard Tschumi during the development of the project for Parc la Villete in 1985. A statement that is inscribed within a comprehension of the concept that in strict sense does not reach the level of a true ontological reflection, but is rather retained in the sphere of cultural critique. For him, the metaphysical dimension of architecture is represented in four historical axioms: dwelling as function (architecture as an object for a subject), the symbolic dimension (architecture as a symbol of cultural categories - power, religion, etc.), architecture as a subordinate medium to this symbolic function, and the will of beauty and formal coherence inherited from the Greeks (Fig. 2)

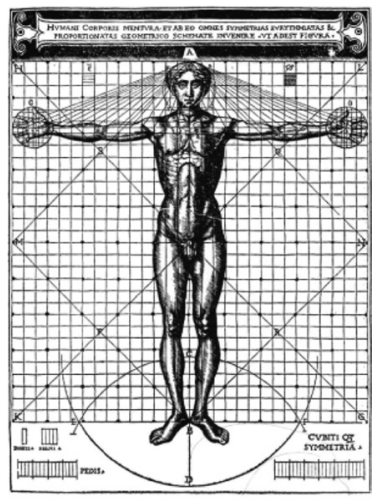

Fig. 1. "Vitruvian Man", illustration in the edition of De architectura by Vitruvius; illustrated edition by Cesare Cesariano (1521). Source: Web, free license.

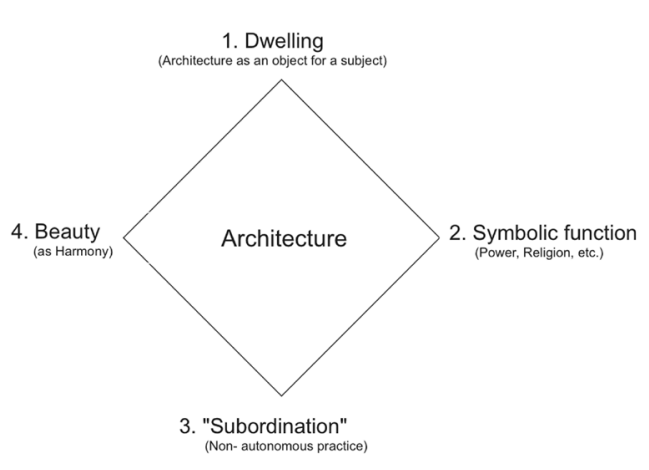

Fig. 2. Diagram of Jaques Derrida's four metaphysical axioms of architecture. Source: author. 
According to Derrida, these four dimensions (or fictions) configure a veil that has historically concealed and avoided the possibility of liberating architecture as a practice open to a plurality of polyvalent meanings, not necessarily congruent. Leaving aside the question if Derrida and his deconstructivist colleagues effectively succeeded in this "liberation crusade", this whole discourse is implicitly inscribed in a critique of normative power structures, the "discourse of power", so characteristic of post-structuralist philosophy oriented towards cultural criticism. Within this theoretical frame, metaphysics and architecture are disposed in an agonal and critical relationship, which can be potentially subverted. The implicit question is evident: What happens to architecture when it is detached from the "burden" of these metaphysical axioms? Does it retain its own specificity? Can it still be named "architecture"?

\section{ARCHITECTURE AND METAPHYSICS: TOWARDS A PHENOMENOLOGICAL INTERPRETATION}

If we attempt to comprehend the link between architecture and metaphysics from a phenomenological perspective, the concepts involved and their relationships are different. Phenomenology, as a method of knowledge linked to the experience of "things themselves", following the original definition by Husserl, is a way that allows us to establish a bridge between sensitive phenomena and its formalisation as abstract theoretical reflection, and as such, has a natural affinity with the field of architecture as an epistemic tool. From this perspective, concepts that have traditionally constituted the core of metaphysical reflection such as being, space and time, find in architecture a privileged medium of manifestation, as concrete existential dimensions that configure our phenomenal experience of being in the world. Seen "through" architecture, as seen through a prism, being becomes existence and space becomes place (locus). What about time? How does this elusive concept embody itself into architecture, and how does this embodiment constitute the particular condition of possibility for a metaphysical language?

\section{ON TIME AND TIMELESSNESS}

Although time manifests itself in nature through the cycle of the seasons, the movement of the celestial bodies, and the vast set of dynamic processes of change that they imply, these are forms of temporal manifestation whose cyclic character leaves them retained in the realm of pure presence, that is to say, they lack direction and meaning. They are primary forms that reaffirm the 
essence of nature as physis, which in its original Greek meaning denotes the neutral substratum that sustains, unfolds and embraces in its bosom the infinity of forms that emerge from it in an incessant blind process without orientation, as manifestations of the principium individuationis, following the interpretation of Schopenhauer. Time acquires direction as an existential dimension primarily through the human faculty of consciousness. It positions us simultaneously as actors and spectators of reality, and facing death as a horizon that encircles our life, giving it measure as a vector with magnitude and direction, like an arrow shot to the horizon. In this state of conscious awareness, being as an abstract ontological category transmutes itself into existence. It is not diluted in the indeterminate, but it is shaped and framed in turn by architecture, understood as the primordial way in which human existence expresses itself as dwelling. This dwelling is crystallised in space and time as an articulation of places conformed by buildings. In them, space is measured by tangible limits, and time is embodied as trace, memory and style. Through architecture, natural time is transmuted into historical time, materialised as a tangible existential coordinate. This ability to materialise time is one of the fundamental metaphysical dimensions of architecture, which is expressed in different levels and ways of manifestation. The first of them is the counterpoint between the inherent will of permanence of the architectural object, as opposed to the flow of becoming.

Any architecture is affirmed as a material fact in a certain will of duration and stability, beyond its potential "metabolic" or dynamic character. Despite wellknown conceptual efforts, ${ }^{2}$ it is not a performative art, which unfolds in real time as a musical piece, but rather a plastic, Apollonian art, whose inner possibility of being is always a synonym of permanence. Architecture does not vanish. It stays. It is the trail of time, the footprint of history. Time passes, architecture tends to remain and "persist" in its presence. It is the silent background on which life takes place as a scene. It is the frame of the canvas on which our daily tasks are traced and our memories are inscribed. This counterpoint between stillness and movement, between the tempo of the stone and the tempo of life, is one of the most primordial forms of the perception of time as an existential coordinate. This attribute is a fundamental constitutive aspect of architecture, an irreducible factor inherent to its purest essence in ontological and phenomenological terms, long transcending the interpretative frameworks associated with its different forms of manifestation at historical, cultural and social levels. As such, it is a dimension that cannot be detached or "deconstructed".

There are architectures in which this perception of time as an existential coordinate can acquire a higher degree of visibility, and here is where we can 
start to think of metaphysics as a formal language which, as such, can present different ways of expression and levels of modulation. In general terms, ruins have this quality (Fig. 3). When we see them, we do not just see a set of "magnificent volumes under the sun", but see time as a concrete materialised dimension. We visit the Greek temple and think of the generations of people who have been there, just like us, admiring this object, but in different stages of its historical development. We see time imprinted in the stone's surfaces and textures, and in the old inscriptions. We see the world, as a vast theater of life and death whose stage is built by architecture, as the frame of a canvas whose content is life itself, with all its greatness and humbleness. And this is an absolute metaphysical experience, which of course in this case is blended with the notions of the sublime and the monumental. ${ }^{3}$

Just as ruins, other architectural objects have the ability of rendering time in a more intentioned and explicit way. At this point, two main strategies must be distinguished: time by timelessness, and time by mimesis (in the sense of "frozen music"). ${ }^{4}$ The references that we have about a metaphysical architecture are more related to the first case, and here it becomes pertinent to make a conceptual link to the work of Giorgio de Chirico. His "Pittura Metafisica" is basically a theatrical representation of the notion of timelessness. A notion that is reinforced by a calculated strategy of contrapunctus: the atemporal stillness of his melancholic urban scenarios is confronted by subtle signs of movement: a flag on top of a tower, a clock, a growing shadow at dusk, a wandering lonely couple (Fig. 4). This is why he prefers the light at sunset, that moment of the day in which light fades and existence is confronted with the presentment of death. This confrontation between the ephemeral and the eternal is the basis of the language of timelessness, understood as an existential Mise-en-scène.

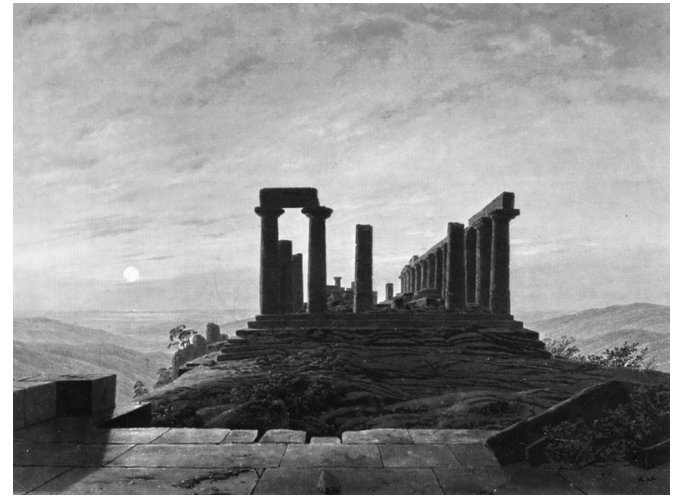

Fig. 3. Caspar David Friedrich, Temple of Juno in Agrigento. Oil on canvas, circa 1828-1830. Source: Web, free license.

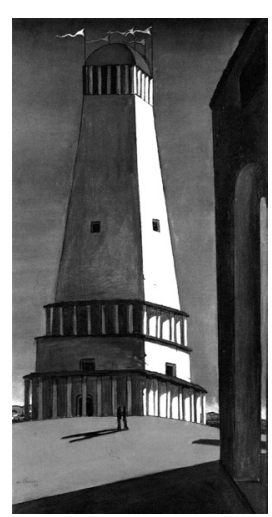

Fig. 4. Giorgio de Chirico, Nostalgia of the infinite. Oil on canvas, 1911. Source: Web, free license. 
In this sense, the use of regular platonic forms like cubes, spheres and pyramids is an efficient way of evoking metaphysical undertones because of their inherent atemporality and sense of perfection and integrity (Fig. 5). Resembling De Chirico's contrapunctus, their timelessness makes the time of their context appear, by contrast. They have this ability of "staging" life in a counterpoint between permanence and flow, between being and becoming. In some cases, this ability is reinforced by other concomitant factors: a sense of mathematical perfection, of absolute congruence and precision in formal-constructive terms. This is the case with the Neue Nationalgalerie building by Mies Van der Rohe (Fig. 6). The mastery of forces and constructive relationships through an adequate use of materials, plus the rendering of time by its inherent atemporality and geometric perfection, makes this object an outstanding case of a metaphysical character combined with the notion of the sublime in its mathematical form. ${ }^{5}$

Now, what is the role of matter in this metaphysics of timelessness language? Doesn't it appear in a way as a complete subordinated principle? Is it possible to integrate it in a more equilibrated way, without destroying the metaphysical expression?

This is the question that has guided the praxis of contemporary architects like Peter Zumthor, for example. His theoretical frame is highly oriented towards phenomenology, with a strong Heideggerian background, and this allows him to value metaphysics not in terms of a detached and abstract reflection, but rather as an existential value, embedded in life and sensitive experience.

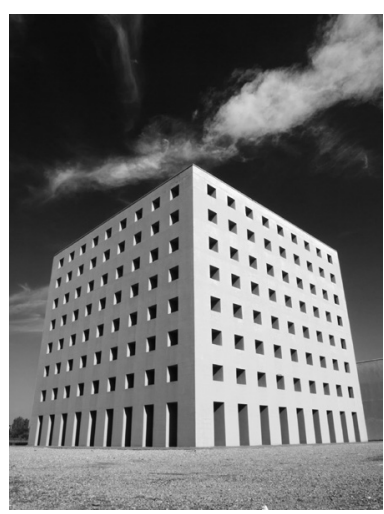

Fig. 5. Aldo Rossi, San Cataldo Cemetery, Modena, 1976. Photo: Maria Lucia Lusetti, Paolo Tedeschi. Source: Wikimedia Commons, authorized for distribution under license CC-BYSA-3.0.

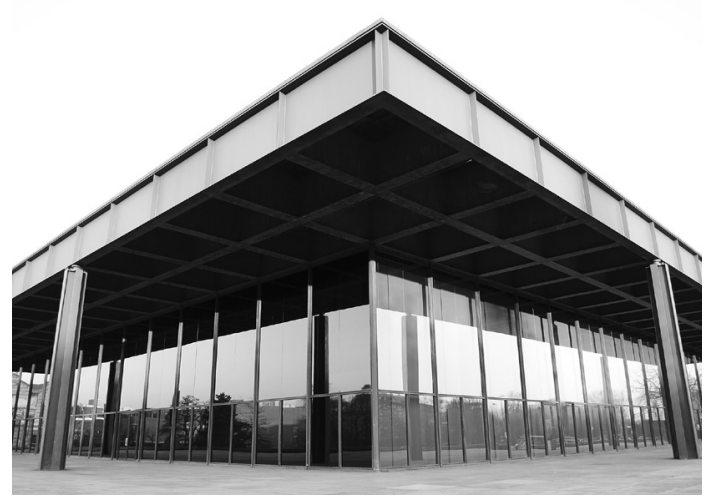

Fig. 6. Mies van der Rohe, Neue Nationalgalerie, Berlin, 1967. Photo: Hans Knips, 2011. Source: Wikimedia Commons, authorized for distribution under license CC-BY-SA-3.0.

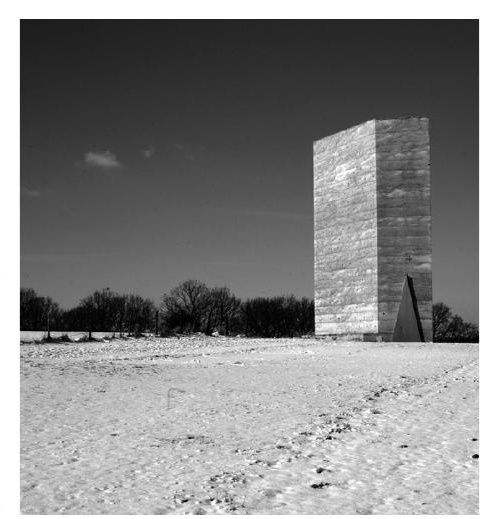

Fig. 7 . Peter Zumthor, Brüder Klaus Kapelle, Metternich, 2007. Photo: René Spitz, 2010. Source: Flickr, authorized for distribution under license CC BYND 2.0. 
His Bruder Klaus Field Chapel in Mechernich, Germany, is an interesting example of this will. Its external appearance speaks the language of the Apollonian timelessness. An abstract prismatic volume, with no representational or mimetic character. A form of pure presence (Fig. 7). But, seen from a closer perspective, subtle details give it a more embodied character: the concrete surface is traced with the marks of the formworks. It has a "skin". A skin that opens through a single triangular door, revealing an internal Dionysian world that apparently contradicts the Apollonian expression of the outside. It appears as a sort of irregular cave, which leads to the place of the altar (Fig. 8). This place, in turn, opens itself to the sky through a circular opening at the top, creating a strong vertical tension reinforced by the textures of the walls, which were created by burning the logs that were originally used as formworks (Fig. 9). The combination of light, its spatial, and tactile properties create a sort of amplified visual and sensitive experience, that is to say, a true atmosphere. But, despite this sensitive accentuation, the space does not lose its sacred character. It remains faithful to its primary function, which is basically to generate an introspective state, which allows the act of worship and praying. Matter becomes an actor of the play, in a leading role, but the script keeps on being metaphysical in its most pure essence. The vertical tension of the space sublimes matter as a vehicle for the incarnation of the spirit, which comes in the form of light, from above, and beyond. Both spirit and matter form an indissoluble alliance, in equilibrium. ${ }^{6}$ An alliance between Meta and Physis, between being and becoming.

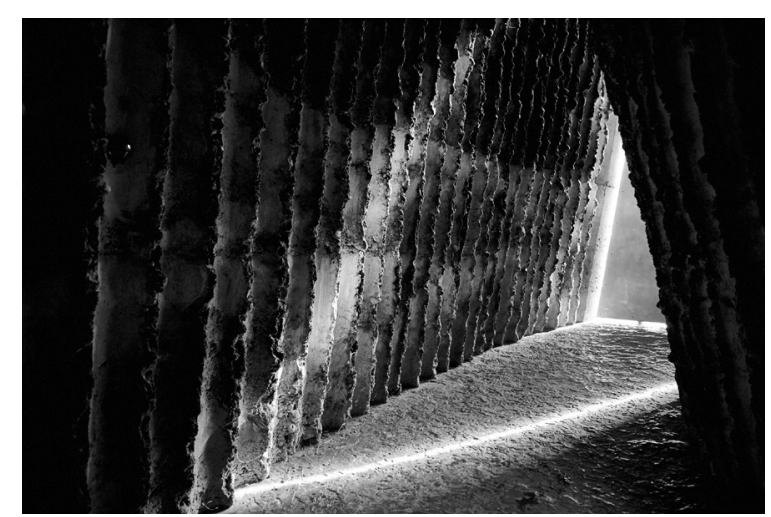

Fi g. 9. Peter Zumthor, Brüder Klaus Kapelle, Metternich, 2007. Photo:

August Fischer, 2016. Source: Flickr, authorized for distribution under
license CC BY-ND 2.0.

August Fischer, 2016. Source: Flickr, authorized for distribution under
license CC BY-ND 2.0.

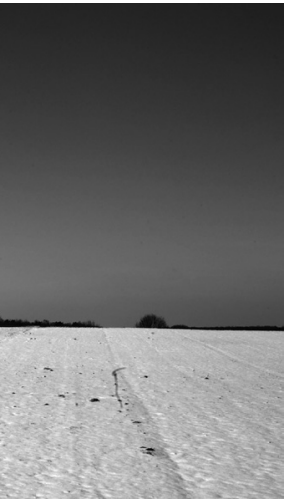

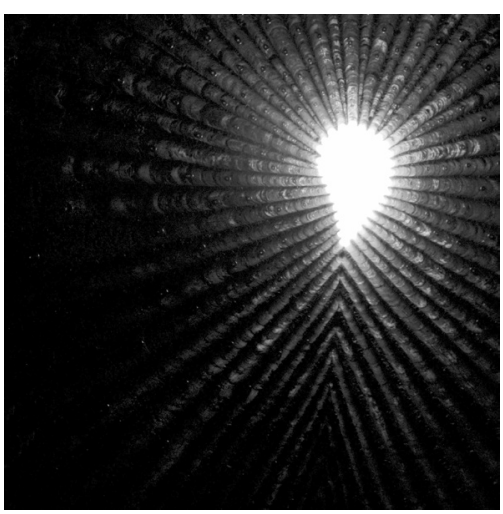

Fig. 9. Peter Zumthor, Brüder Klaus Kapelle, Metternich, 2007. Photo: Seier+Seier, 2008. Source: Flickr, free license. 
A characteristic example of this conception is represented by Archigram's utopic views like "PlugIn City" and "Instant City", and all their contemporary derivations, mainly still concentrated in Architectural Association's programmatic orientations.

Regarding this relationship, a subtle distinction must be made: The language of the metaphysical in architecture is always sublime, but the sublime does not always imply the metaphysical. The products of the contemporary "digital sublime" are more oriented towards the "aesthetics of miracle", as Jean Nouvel calls it. They "mimic" time, thus they have a more representational character.

This distinction can be stylistically extrapolated from the Classic - Baroque duality.

The distinctive use of the grid as a dispositive of modulation, an invisible layer that rules the spatial configuration of the whole, can be interpreted as an efficient "metaphysical tool" applied in the design process.

"Architecture is the only art that settles with authentic peace, the grand contest between the will of the spirit and the necessities of nature, which are resolved in an exact equilibrium, the adjustment of accounts between the soul which tends to the above and the gravity which pulls towards the below." George Simmel, The Ruin. 
Harries, Karsten. The ethical function of Architecture. Cambridge, MIT Press, 2000.

Heidegger, Martin. Basic writings. Edited by David Farrel Krell. New York, Harper \& Collins editors, 1993.

Merleau-Ponty, M. Phenomenology of perception. London, Routledge, 1962.

Nietzsche, F.W. El nacimiento de la tragedia. Madrid, Alianza Editorial, 2009

Norberg-Schulz, C. Genius Loci: Towards a phenomenology of Architecture. New York, Rizzoli, 1980.

Pallasmaa, J. The eyes of the skin. Architecture and the senses. London, Academy editions, 1996.

Reza Shirazi, M. Towards an articulated phenomenological interpretation of Architecture. New York, Routledge, 2014.

Schopenhauer, A. El mundo como voluntad y representación, vol. I, II. Madrid, Akal Ediciones, 2010 . 